\title{
Influencing Factors and Improvement Strategies for Indoor Air Quality and Human Thermal Comfort in a Convenience Store
}

\author{
Yu-Chieh Chen ${ }^{1}$, Shih-Yu Chang1, Chung-Hao Cheng ${ }^{1}$, Chin-Ching Wu ${ }^{2 *}$ \\ ${ }^{1}$ Department of Public Health, Chung Shan Medical University, Taiwan \\ ${ }^{2}$ Department of Public Health, China Medical University, Taiwan \\ Email: *wucc@mail.cmu.edu.tw
}

How to cite this paper: Chen, Y.-C., Chang, S.-Y., Cheng, C.-H. and Wu, C.-C. (2018) Influencing Factors and Improvement Strategies for Indoor Air Quality and Human Thermal Comfort in a Convenience Store. Health, 10, 215-227.

https://doi.org/10.4236/health.2018.102018

Received: January 31, 2018

Accepted: February 25, 2018

Published: February 28, 2018

Copyright ( $) 2018$ by authors and Scientific Research Publishing Inc. This work is licensed under the Creative Commons Attribution International License (CC BY 4.0).

http://creativecommons.org/licenses/by/4.0/

(c) (i) Open Access

\begin{abstract}
Indoor air quality has received increased attention. Surveying human thermal comfort and evaluating indoor airflow and ventilation can improve the integrity assessment of the indoor environment. In this study, indoor air quality measurements and spatial assessments were performed in a convenience store on a campus. The computational fluid dynamics model was used to simulate the indoor airflow and explore the spatial distribution of the $\mathrm{CO}_{2}$ concentration. The results showed the $\mathrm{CO}_{2}$ concentration easily surpassed the standard value during the weekdays and accumulated in short flows and dead zones. In the condition of no-building alterations, the preferred improvement strategy is to modify the air supply angle to $30^{\circ}$.
\end{abstract}

\section{Keywords}

Carbon Dioxide, Computational Fluid Dynamics, Simulation, Ventilation

\section{Introduction}

The Taiwan Environmental Protection Agency (TEPA) enacted the "Indoor Air Quality (IAQ) Management Act" on November 8, 2011, and implemented the act on November 23, 2012. The IAQ standard documents standard concentrations for nine indoor air pollutants, including carbon dioxide $\left(\mathrm{CO}_{2}\right)$, carbon monoxide ( $\mathrm{CO})$, formaldehyde ( $\mathrm{HCHO})$, total volatile organic compounds (TVOC), bacteria, fungi, suspended particulates $\left(\mathrm{PM}_{2.5}\right.$ and $\left.\mathrm{PM}_{10}\right)$, and ozone $\left(\mathrm{O}_{3}\right)$. Man-made combustion and occupant breathing are primary sources of indoor $\mathrm{CO}_{2}$. Occupant breathing is regarded as one of the major source in general public spaces. $\mathrm{CO}_{2}$ is generally used as an indicator to assess appropriate indoor 
occupant density and ventilation rate. The outdoor concentration of $\mathrm{CO}_{2}$ generally varies from 350 to $450 \mathrm{ppm}$, however, the standard IAQ concentration of $\mathrm{CO}_{2}$ is $1000 \mathrm{ppm}$. High indoor $\mathrm{CO}_{2}$ concentrations in an office environment may increase the transcutaneous $\mathrm{CO}_{2}$ level and lead to sleepiness during cognitive work [1].

Average persons spend $80 \%-90 \%$ of their time daily in the indoor environment. Thus, IAQ is of increasing concern in research on human health. Factors that affect indoor airflow and distribution mainly include: 1) the size, location, and form of air conditioning outlets and return air inlets; 2) air velocity and air volume from supply air outlets; 3 ) temperature differences between outlet airflow and indoor air; 4) type of ventilation equipment; 5) intensity and location of the heat source; 6) the size and geometric shape of the indoor space; and 7) the layout of furniture or equipment. Previous studies have noted that providing a good indoor airflow and ventilation can improve IAQ and meet the specification standard for human thermal comfort (HTC) [2]-[7]. Efficient ventilation provides clean air to reduce the occurrence of sick building syndrome and thus guarantee the health, thermal comfort, and work efficiency of indoor occupants [8] [9]. It should be taken into account that the benefits resulting from the adoption of strategies to improve IAQ outweigh the investment [10].

The main purpose of this study was to investigate factors associated with indoor $\mathrm{CO}_{2}$ concentration in a convenience store. We also discussed the relationship between indoor airflow and spatial distribution of $\mathrm{CO}_{2}$ concentration. Strategies and recommendations for improvements were provided.

\section{Methods}

This study was conducted in a convenience store on the campus of a medical university in Central Taiwan. The spatial dimensions of the indoor environment were $17.3 \mathrm{~m} \times 6.8 \mathrm{~m} \times 3.0 \mathrm{~m}$ (length $\times$ width $\times$ height), with a floor area of 117.6 $\mathrm{m}^{2}$. The ventilation equipment was a central air conditioning system. Five sampling points in the indoor environment and one sampling point in the outdoor space were set for IAQ measurements. Figure 1 illustrates the shop architecture, interior design pattern and sampling sites. HTC was measured according to ISO7730 (2004) and ASHARAE Standard 55 (2005). As required by the above two international standards, the height of measurement was within the breathing zone, i.e., $1.1-1.7 \mathrm{~m}$. This height range was therefore used in the present study.

The measurements included three items: chemical pollutant, physical environment, and occupants. The chemical pollutant was chosen according to the characteristics of the indoor environment. The $\mathrm{CO}_{2}$ concentration in the convenience store tends to increase in the crowd rush hour when customers go shopping. Thus, we chose $\mathrm{CO}_{2}$ as the chemical pollutant to measure. Temperature, relative humidity and air velocity were physical environment factors measured to investigate HTC and indoor airflow pattern. These items were used not only to calculate HTC but also to simulate indoor airflow patterns and to verify 
the simulation results. We used the number of invoices to assess the number of customers in the store during different time periods.

The commercial computational fluid dynamic software (Solidwork 2013) was used to evaluate the performance of different improved suggestions. The indoor air fluid was simulated by changing the number, type and position of air supply outlets, return air inlets, and vans. The CFD analysis parameters of different air conditioners are shown in Table 1.

\section{Results}

\subsection{Measurement and Spatial Distribution of $\mathrm{CO}_{2}$ Concentration}

During December 29 - 31, 2013, IAQ measurements and HTC surveys were conducted in the convenience store on campus. Each day was divided into five periods from 07:30 to 17:30. Figure 2 shows that the $\mathrm{CO}_{2}$ concentration was paralleled to the number of customers in the store. Measurements of both indoor $\mathrm{CO}_{2}$ concentrations and customers were higher on weekdays than on weekends, except for $\mathrm{CO}_{2}$ measured at points $\mathrm{C}$ and $\mathrm{D}$. The $\mathrm{CO}_{2}$ values were greater than the standard value of $1000 \mathrm{ppm}$ at 13:00. The measurements of relative humidity and temperature at different points were presented in Table 2.

\subsection{HTC between Model and Survey}

Table 3 showed the surveyed HTC in the indoor environment. The results

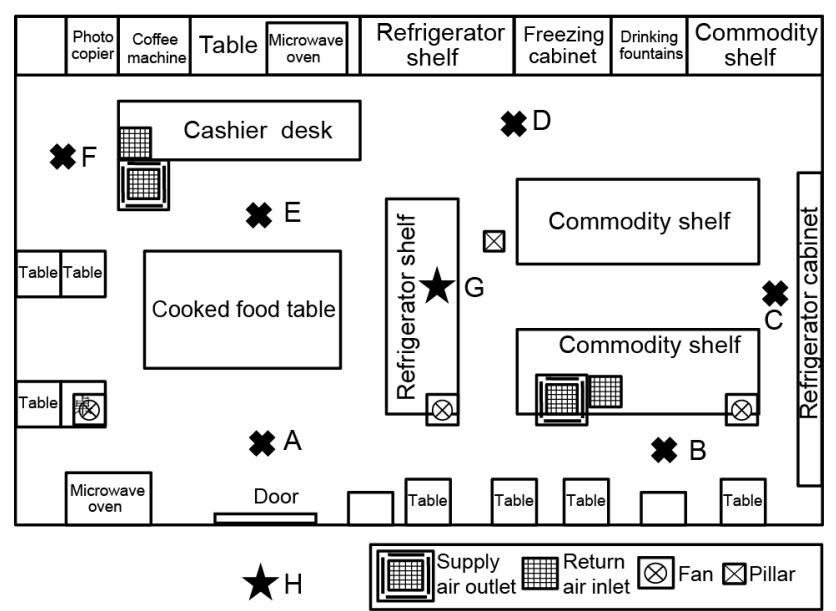

(a)

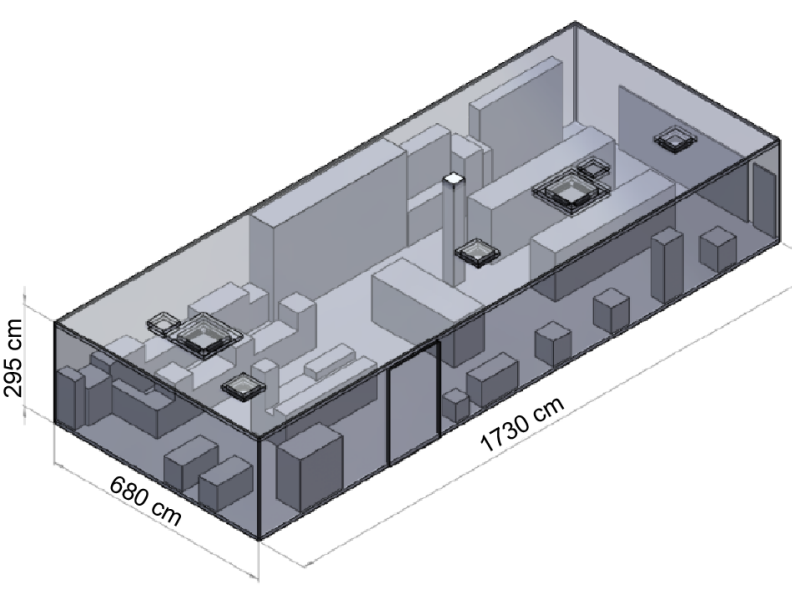

(b)

Figure 1. The convenience store layout and sampling point locations, where the simplified furniture arrangements were used in CFD simulations.

Table 1. The CFD analysis parameters of different air conditioners.

\begin{tabular}{cc}
\hline Airconditioner & Boundary condition \\
\hline Supply air outlet & Velocity: $0.7 \mathrm{~m} / \mathrm{s}$, Temperature: $299 \mathrm{~K}$ \\
Return air inlet & Velocity: $0.4 \mathrm{~m} / \mathrm{s}$, Temperature: $299 \mathrm{~K}$ \\
Fan & Static pressure, Temperature: $303 \mathrm{~K}$ \\
\hline
\end{tabular}


(a)

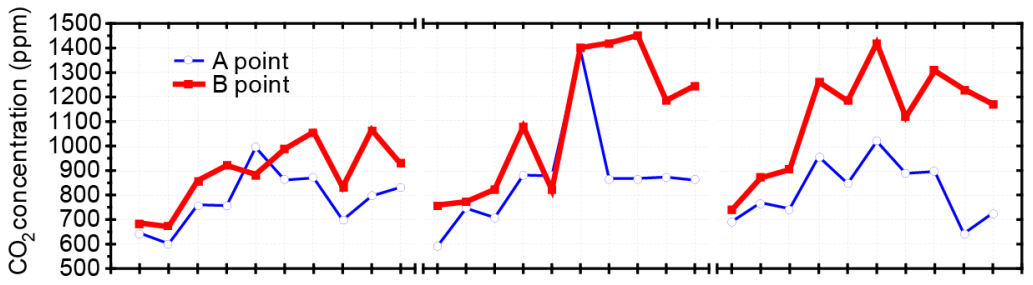

(b)

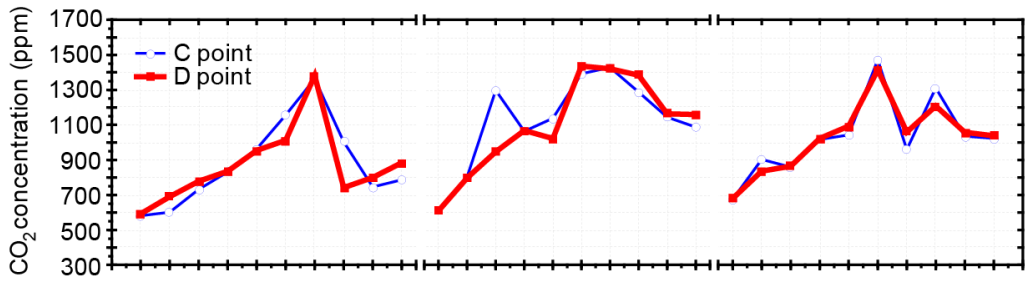

(c)

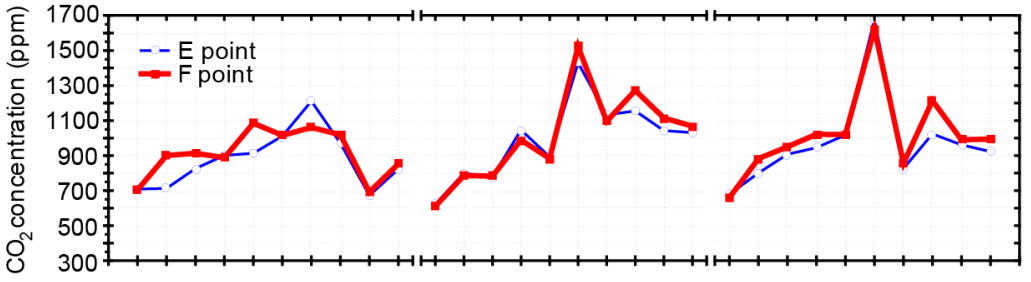

(d)

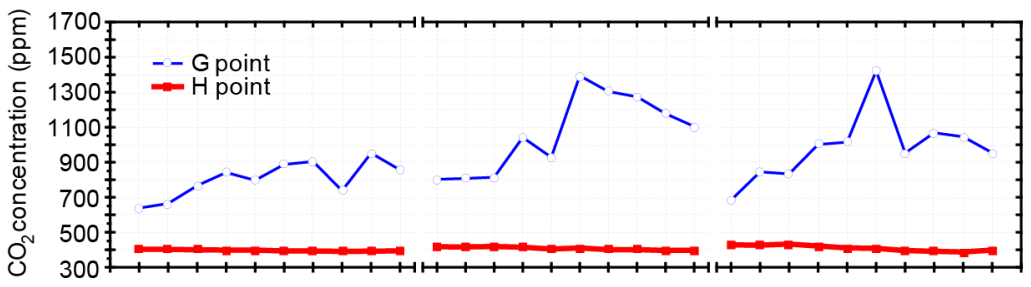

(e)

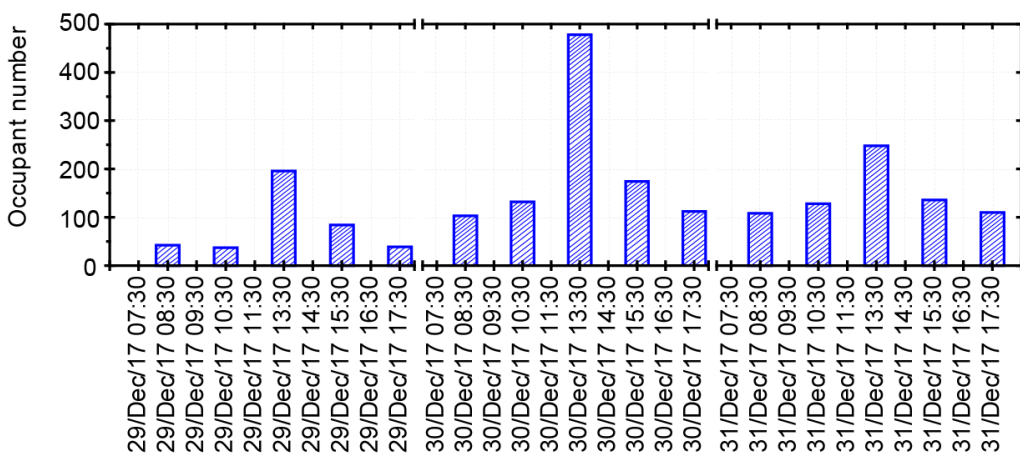

Figure 2. The time variations of occupants and $\mathrm{CO}_{2}$ concentrations in the convenience store.

Table 2. The environmental factors at different points in the store.

\begin{tabular}{ccc}
\hline Point & Relative humidity $(\%)$ & Temperature $\left({ }^{\circ} \mathrm{C}\right)$ \\
\hline A & $48.2 \pm 3.5$ & $21.9 \pm 1.4$ \\
B & $48.3 \pm 3.3$ & $21.0 \pm 1.3$ \\
C & $46.3 \pm 2.9$ & $21.2 \pm 1.3$ \\
D & $47.5 \pm 3.6$ & $20.9 \pm 1.3$ \\
E & $47.7 \pm 3.7$ & $21.5 \pm 1.5$ \\
F & $45.5 \pm 3.6$ & $22.4 \pm 1.3$ \\
G & $47.8 \pm 4.4$ & $21.6 \pm 1.5$ \\
H & $47.2 \pm 2.9$ & $19.5 \pm 2.1$ \\
\hline
\end{tabular}


Table 3. The survey results of thermal comfort sensations.

\begin{tabular}{cc}
\hline Thermal comfort sensation & Survey number (percentage) \\
\hline Hot & $2(1.8 \%)$ \\
Warm & $5(4.4 \%)$ \\
Slightly warm & $23(20.4 \%)$ \\
Neutral & $54(47.8 \%)$ \\
Slightly cool & $19(16.8 \%)$ \\
Cool & $9(8.0 \%)$ \\
Cold & $1(0.9 \%)$ \\
\hline
\end{tabular}

revealed that with regard to the subjects' sensation of temperature, a neutral state accounted for the highest proportion. The indoor environment complied with international normative standards as specified by ASHARAE Standard 55. However, the $\mathrm{CO}_{2}$ concentration surpassed the standard IAQ value.

\subsection{Computational Fluid Dynamics Analysis}

Figure 3 presents the indoor airflow distribution of computational fluid dynamics (CFD) simulation in the original space of the indoor environment. Figure 3(a) and Figure 3(b) show that the air velocity was relatively low in local areas in the space, resulting in dead zones. These dead zone areas were mainly between two store shelves in the upper right and near the cashier desk in the upper left of the figure. Figure 3(c) and Figure 3(d) clearly show that the airflow from the supply air outlet directly enters into the return air inlet, leading to a short circuit.

In fact, four measurements points $(\mathrm{B}, \mathrm{C}, \mathrm{D}, \mathrm{F})$ with higher $\mathrm{CO}_{2}$ concentrations corresponded to dead zones in the indoor airflow distribution. Because the indoor ventilation design and indoor airflow were affected by the arrangement of interior furnishings, leading to low air velocity in local areas and thus became dead zones. As a consequence, $\mathrm{CO}_{2}$ easily accumulated in these areas and surpassed the standard value. Moreover, a short circuit was caused due to the close proximity of the supply air outlet to the return air inlet.

\subsection{Improvement Strategy Assessment}

Appropriate strategies were needed to improve the indoor distributions of $\mathrm{CO}_{2}$ concentrations, especially in the dead zone and low velocity area. In this study, improvement strategies were to modify the indoor airflow distributions to reduce $\mathrm{CO}_{2}$ accumulations in the indoor environment. Here, Solid Works 2013 software was used to perform CFD simulation analysis of indoor airflow distribution to assess indoor ventilation in the indoor environment. The improvement strategies include door opening, increased return air inlets, modifying the air supply angle for the ventilation opening, horizontal ventilation, and displacement ventilation (Figure 4). 
(a)
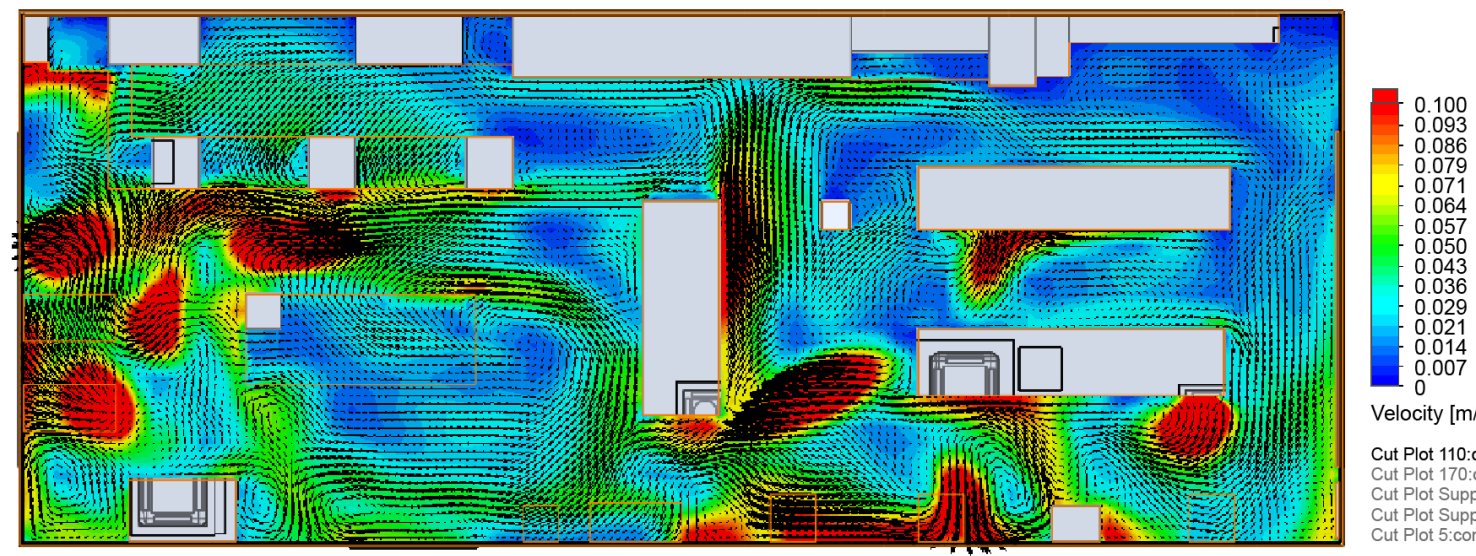

Velocity [m/s]

Cut Plot 110:contours

Cut Plot 170: contours

Cut Plot Supply1: contours

Cut Plot Supplyz:con
Cut Plo 5:contours

(b)
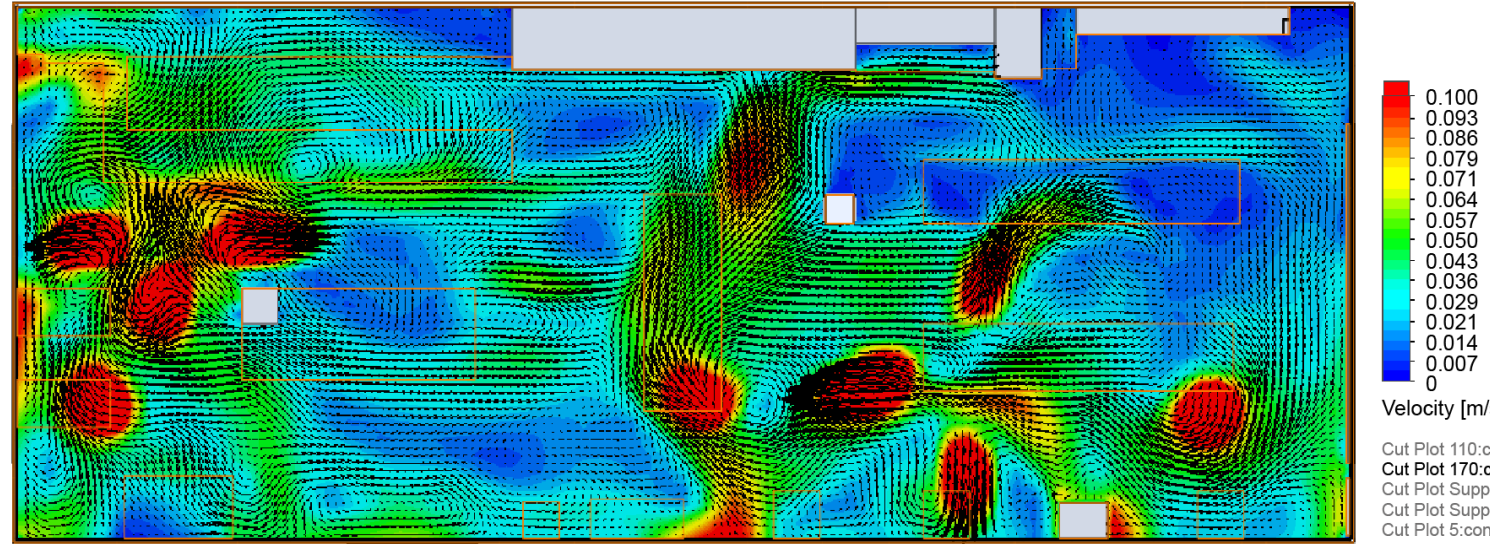

Velocity $[\mathrm{m} / \mathrm{s}]$

Cut Plot 110:contours

Cut Plot Supply2:contours

Cut Plot 5:contours

(c)
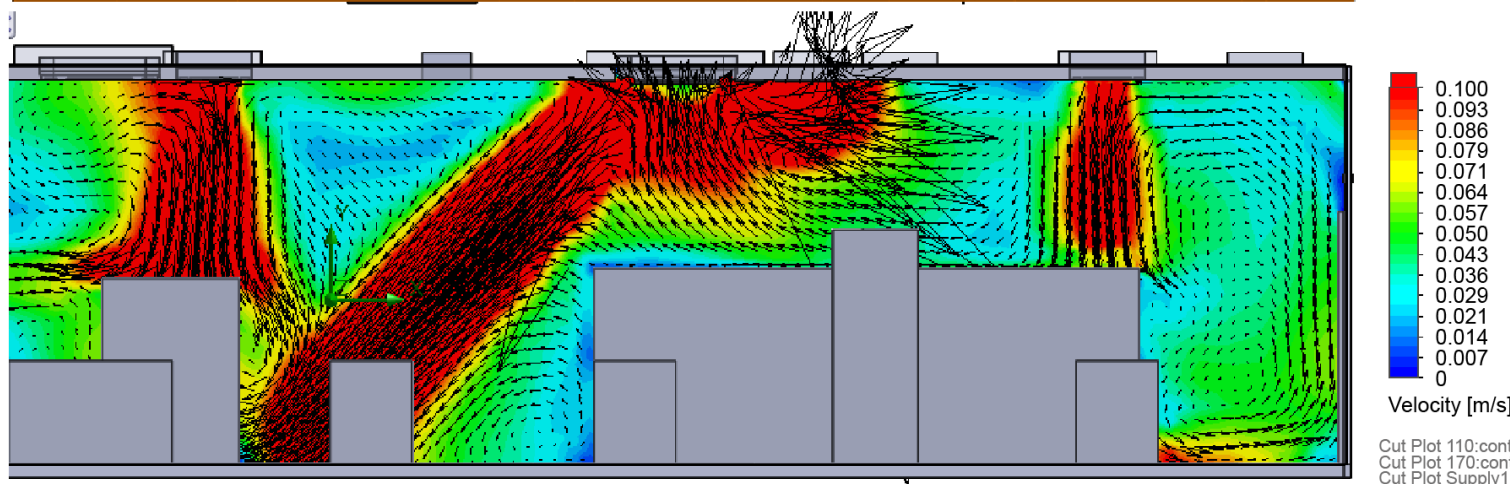

Velocity $[\mathrm{m} / \mathrm{s}]$

Cut Plot 110:contours
Cut Plot 170 : contours

(d)

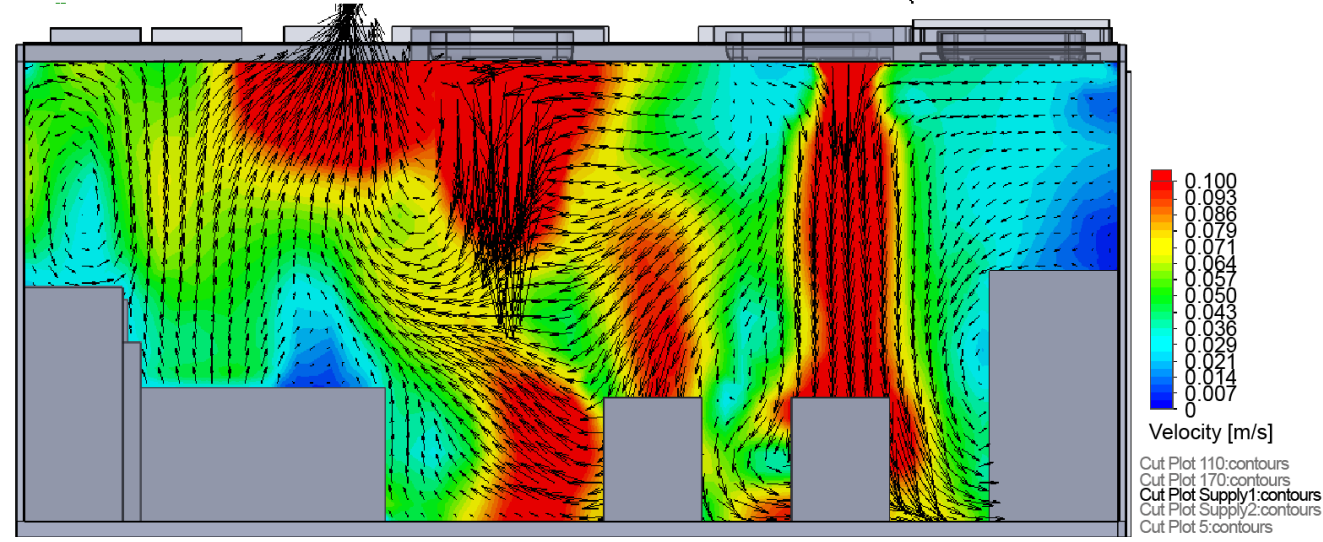

Figure 3. The airflow distribution of CFD simulation in the original space. (a) a top view at $110 \mathrm{~cm}$; (b) a tap view at $170 \mathrm{~cm}$; (c) a lateral view on the side of the house; (d) a lateral view in front of the cashier desk. 


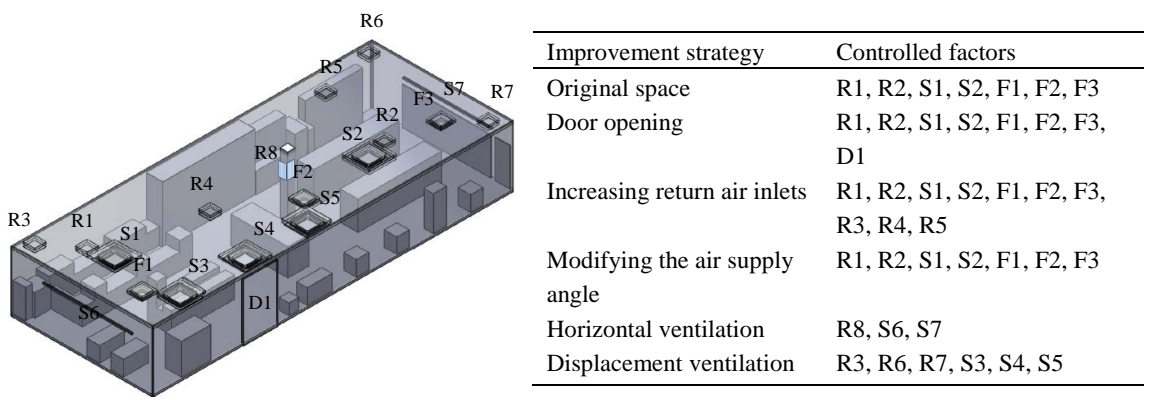

Figure 4. The controlled factors of improvement strategies. (R: return air inlet; S: supply air outlet; F: fan; D: door).

\section{- Door opening:}

Figure 5 shows the airflow distribution in the indoor environment after door opening. In this figure, (a) and (b) show the airflow distribution at different heights, wherein part of the dead zone areas with low air velocity in the airflow distribution in the original space were improved; however, dead zone remained in some areas in the space. Figure 5(c) and Figure 5(d) are vertical airflow distribution maps of the supply air outlet. The short-circuit phenomenon in the original space improved after door opening, mainly because the opening door leaded the airflow to move towards the door side and increased airflow in the space, thereby the areas of dead zone reduced in the indoor environment. The airflow originally flowing into the return air inlet was driven by other airflow to flow towards the door side, thus improving the short circuit.

- Increasing and modifying return air inlets:

The strategy for increasing the number and modifying the location of the return air inlets was to use three return air inlets and modify the location to an appropriate distance to the ventilation opening and fan as well as the areas prone to forming dead zones. Figure 6 indicates that some areas remain with low air velocity resulting dead zones. Figure 6(e) shows that the airflow was restricted by interior furnishings and thus could not fully move around the entire space after increasing and modifying the return air inlets. Nonetheless, the original short circuit was improved by changing the position of the return air inlets.

The next strategy was modifying the air supply angle of the ventilation opening from $45^{\circ}$ to $30^{\circ}$. When the air supply angle was adjusted upwards to $30^{\circ}$, the magnitude of air supply became wider, and the dead zone areas were markedly reduced compared to those in the original space (Figure 7). Figure 7(e) shows that this design was less affected by interior furnishings and that it enabled the airflow to fully move around the entire space.

- Horizontal ventilation supplies air from both sides:

Horizontal ventilation supplies air from both sides, with a return air inlet set on the central pillar at the same height as the supply air outlet. Figure 8(a) and Figure 8(b) present the airflow distribution at the heights of 170 and $110 \mathrm{~cm}$, respectively. Because the interior furnishings were arranged horizontally, the horizontal airflow could easily move throughout the whole space in the indoor 
(a)
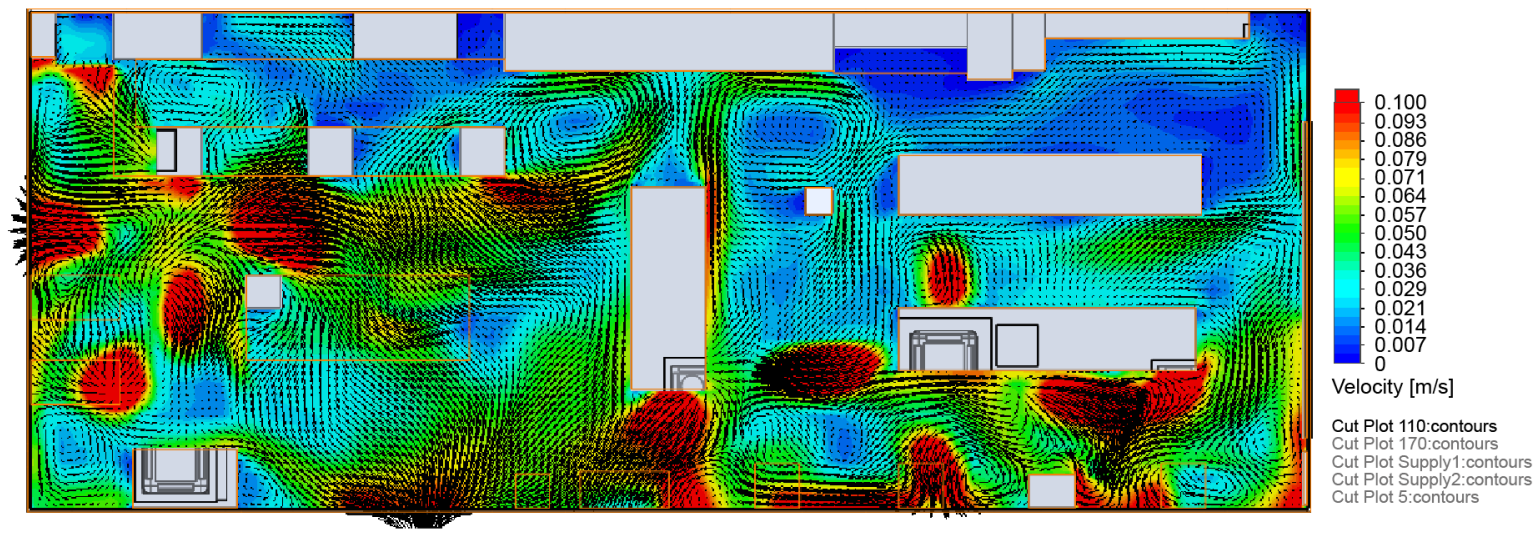

(b)
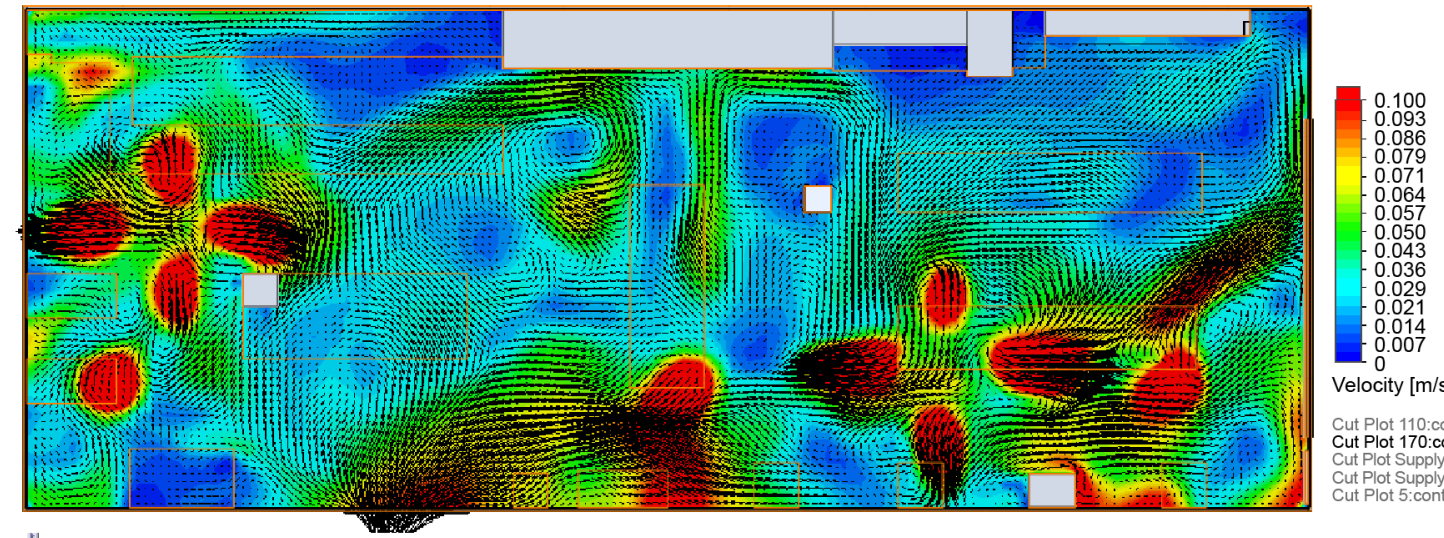

(c)
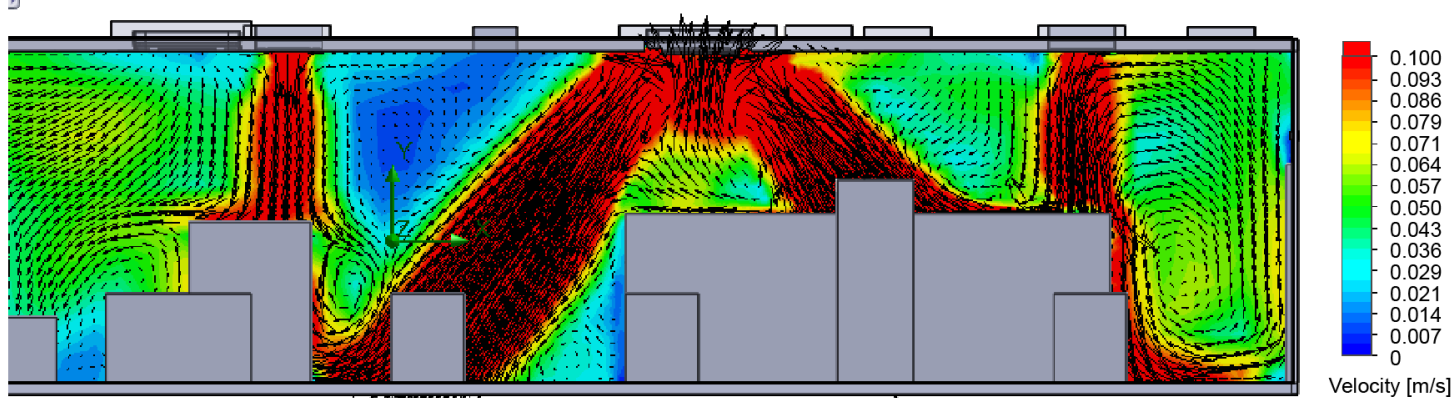

(d)
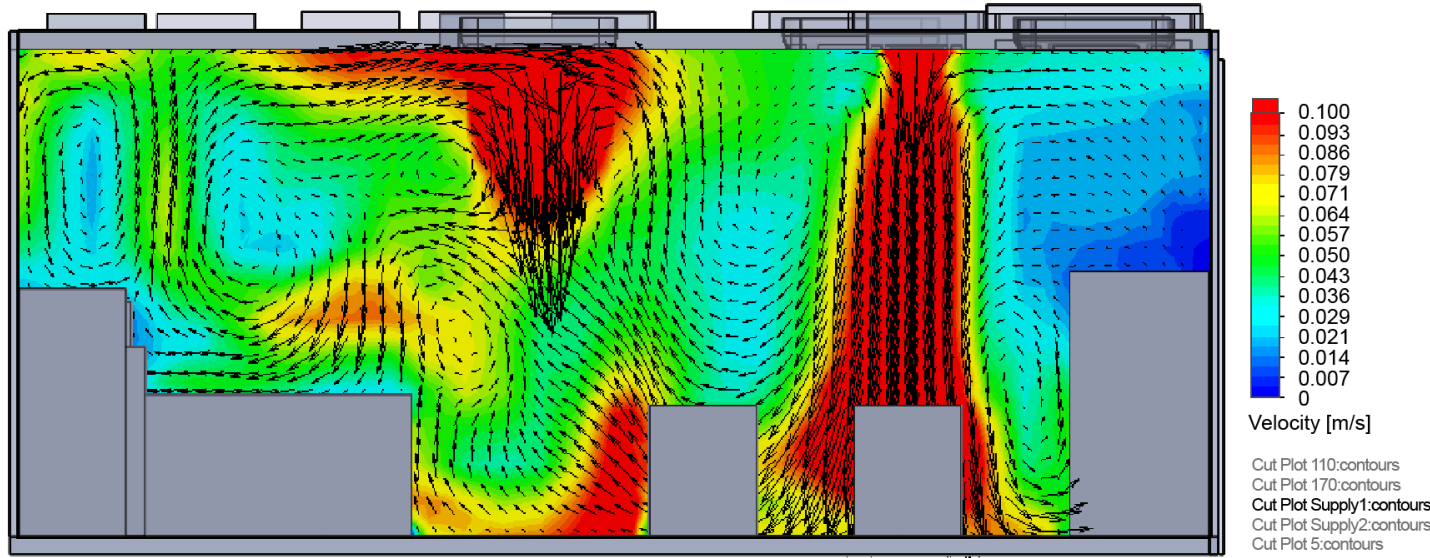

Figure 5. The airflow distribution of CFD simulation in the convenience store according to improvement strategy of door opening. (a) a top view at $110 \mathrm{~cm}$; (b) a tap view at $170 \mathrm{~cm}$; (c) a lateral view on the side of the house; (d) a lateral view in front of the cashier desk. 
(a)

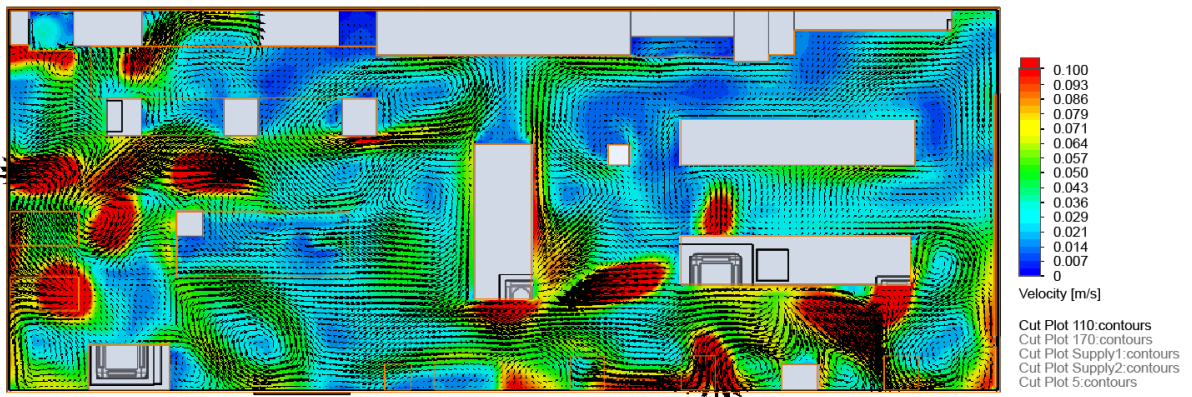

(b)

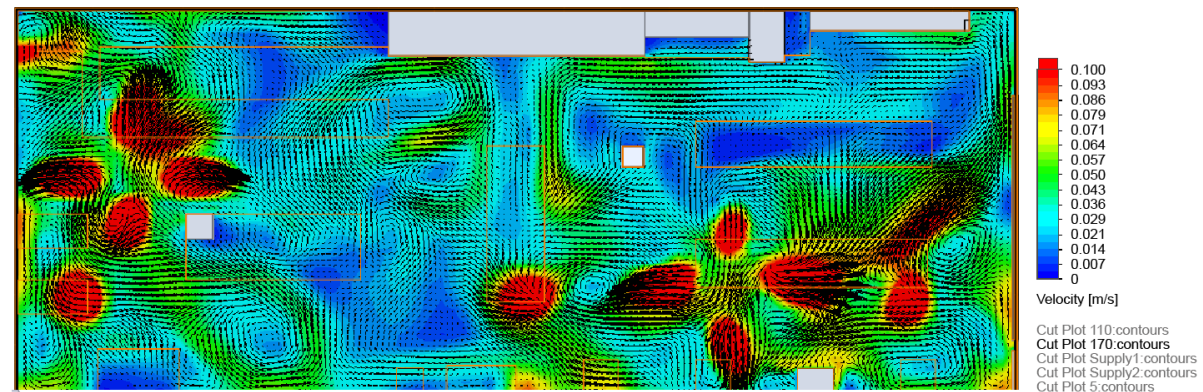

(c)
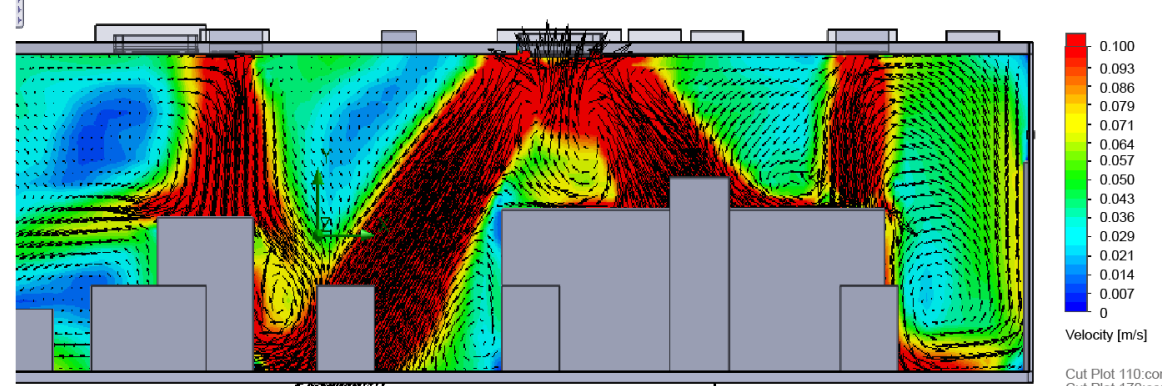

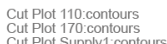

(d)
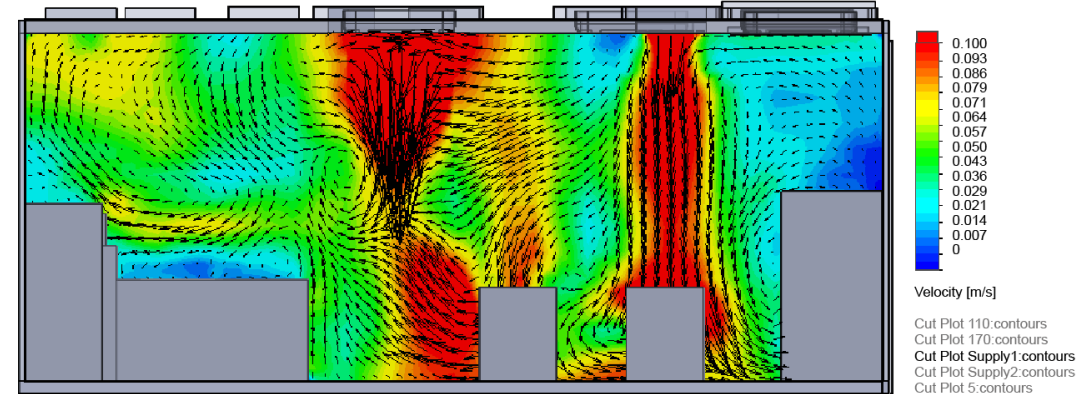

(e)

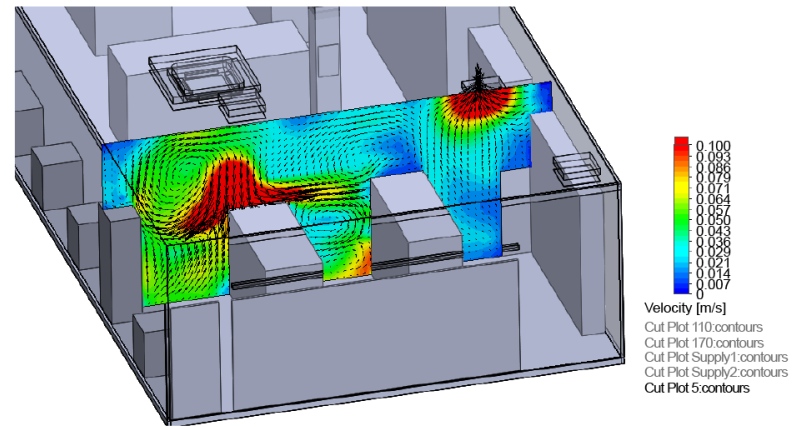

Figure 6. The airflow distribution of CFD simulation in the convenience store according to improvement strategy of increasing and modifying return air inlets. (a) a top view at $110 \mathrm{~cm}$; (b) a tap view at $170 \mathrm{~cm}$; (c) a lateral view on the side of the house; (d) a lateral view in front of the cashier desk; (e) a vertical airflow distribution of the supply air outlet. 
(a)
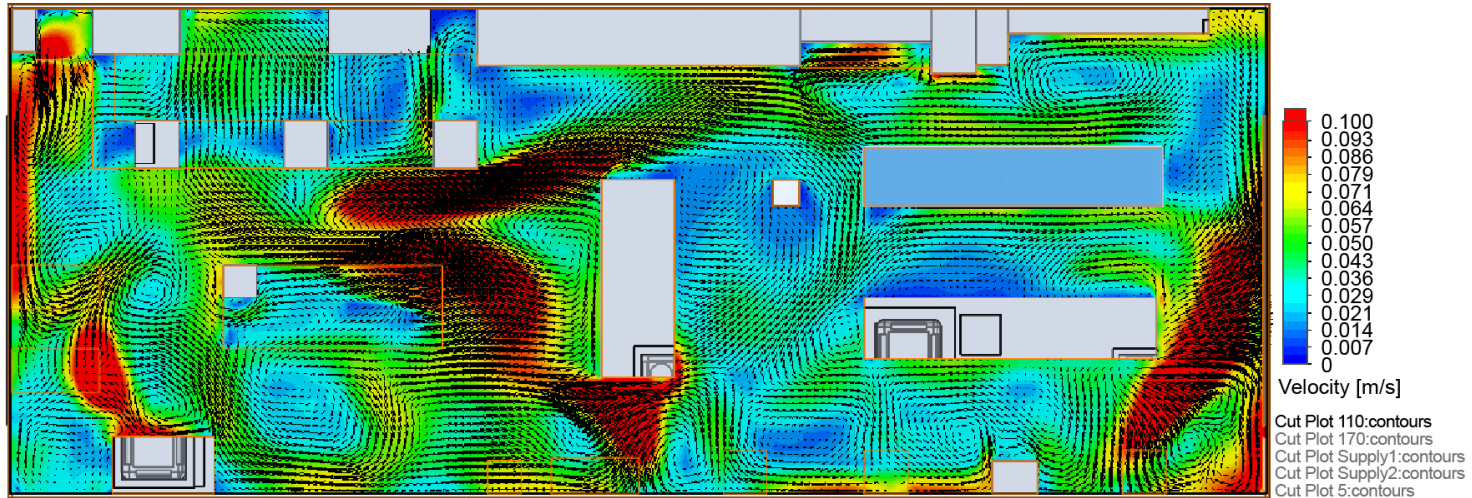

(b)

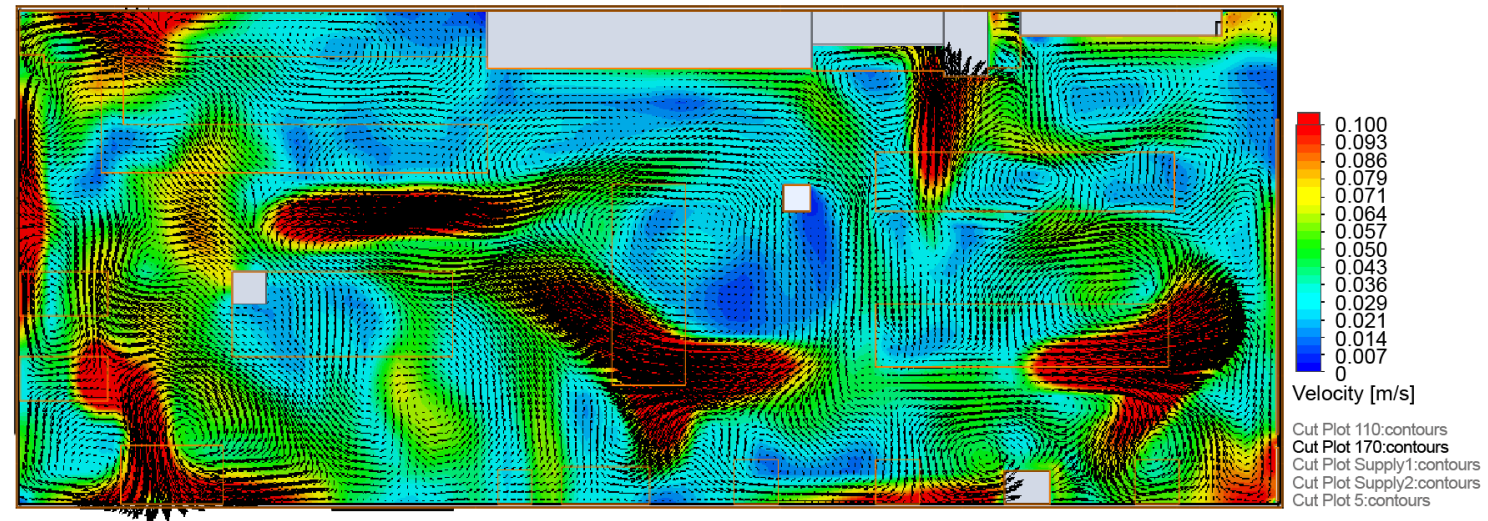

(c)
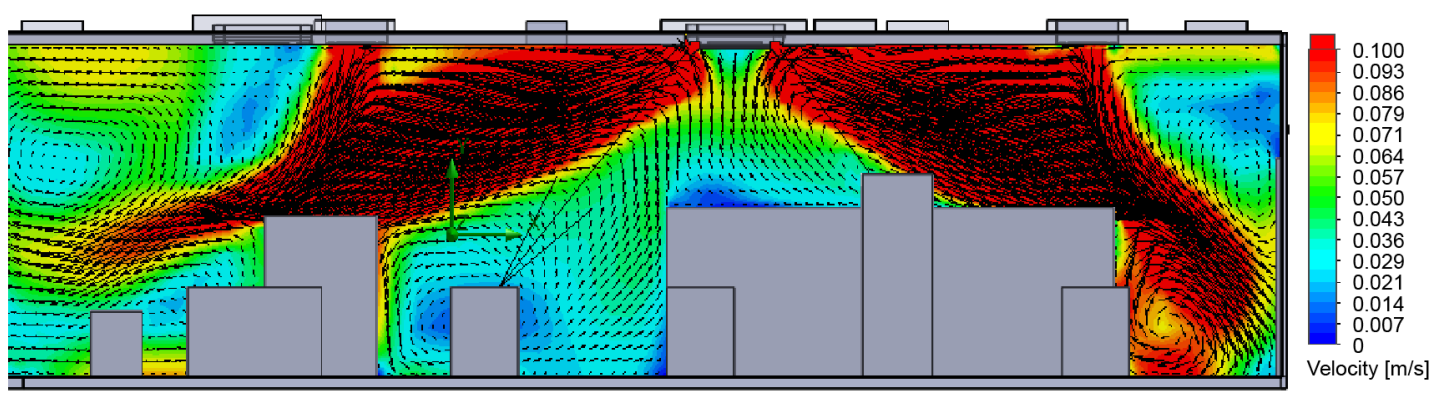

Cut Plot 110:contours Cut Plot 170:contours Cut Plot Supply1: contours

(d)
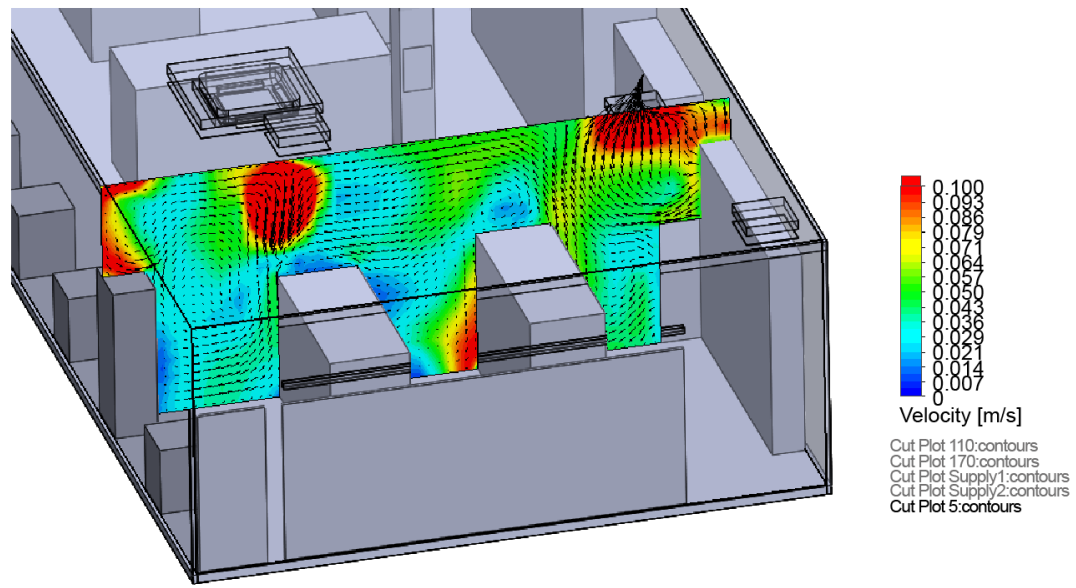

Figure 7. The airflow distribution of CFD simulation in the convenience store according to improvement strategy of modifying the air supply angle of the ventilation opening. (a) a top view at $110 \mathrm{~cm}$; (b) a tap view at $170 \mathrm{~cm}$; (c) a lateral view on the side of the house; (d) a lateral view in front of the cashier desk. 
(a)
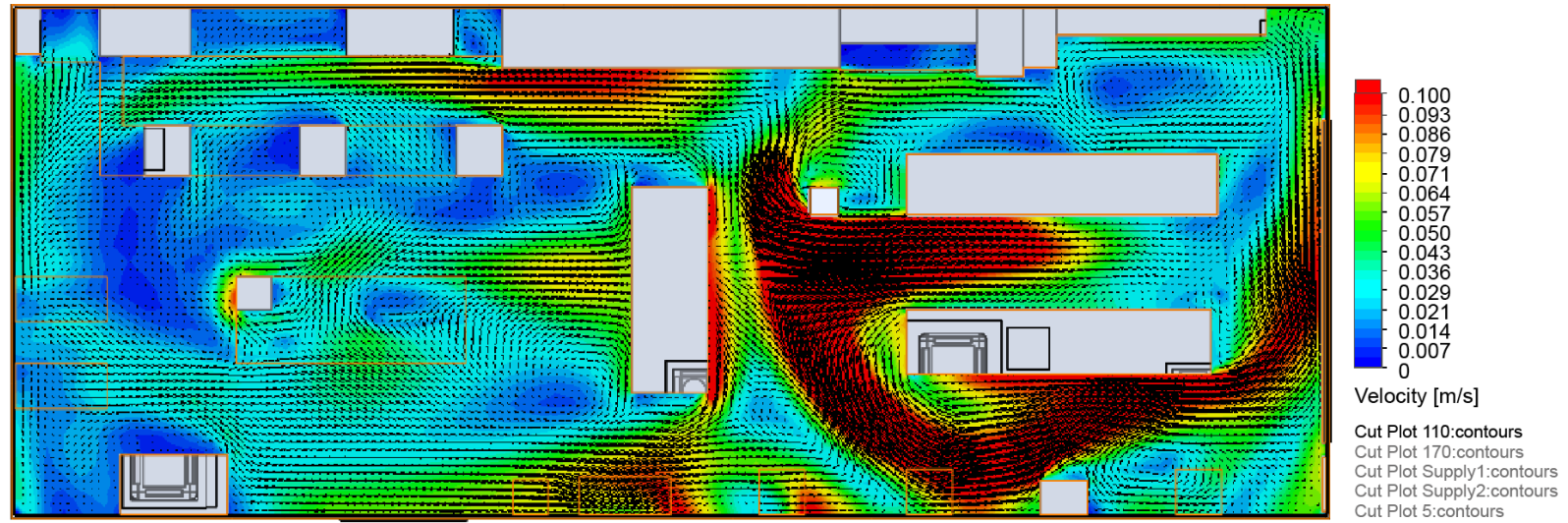

(b)
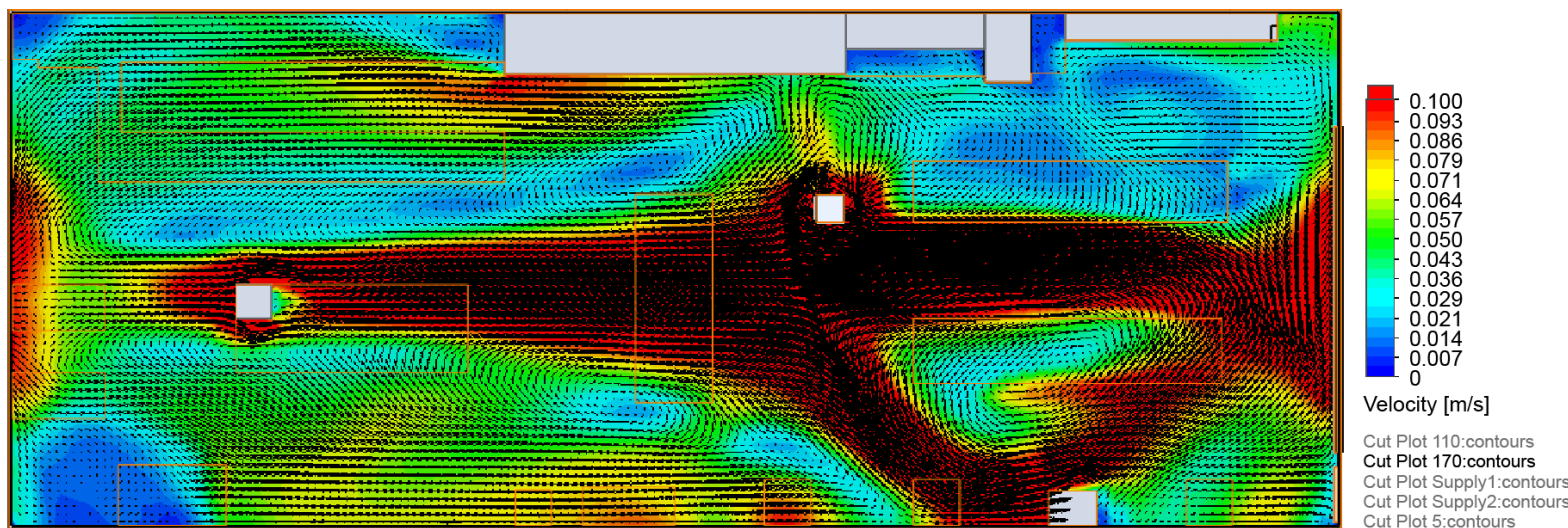

Figure 8. The airflow distribution of CFD simulation in the convenience store according to improvement strategy of horizontal ventilation supplies air from both sides. (a) a top view at $110 \mathrm{~cm}$; (b) a tap view at $170 \mathrm{~cm}$.

environment. There are few dead zone areas and no short circuits.

- Displacement ventilation:

The displacement ventilation strategy is to set up an exhaust vent in the corner of the space, install a supply air outlet at the door and on both sides of the door, and leave the door open. This strategy used air supply from the outlet and natural ventilation to bring fresh air into all of the corners of the space and to discharge air pollutants from the space via the exhaust vent, thereby achieving displacement ventilation. This design enables airflow to easily move around the entire space. There were rarely any dead zone areas, and the short-circuit phenomenon did not occur (Figure 9). It is easy to control the concentration of air pollutants in line with the standard values using this strategy.

Finally, we compared the indoor airflow distributions of all proposed strategies by considering the results of airflow improvement and the cost. The preferred ventilation methods include displacement ventilation, horizontal ventilation, and modifying the air supply angle to $30^{\circ}$. The second-best strategies include opening the door and increasing the number/changing the position of ventilation openings. If not considering interior decoration work and given the limit of expenditure, modifying the air supply angle to $30^{\circ}$ is the optimal improvement strategy. 
(a)
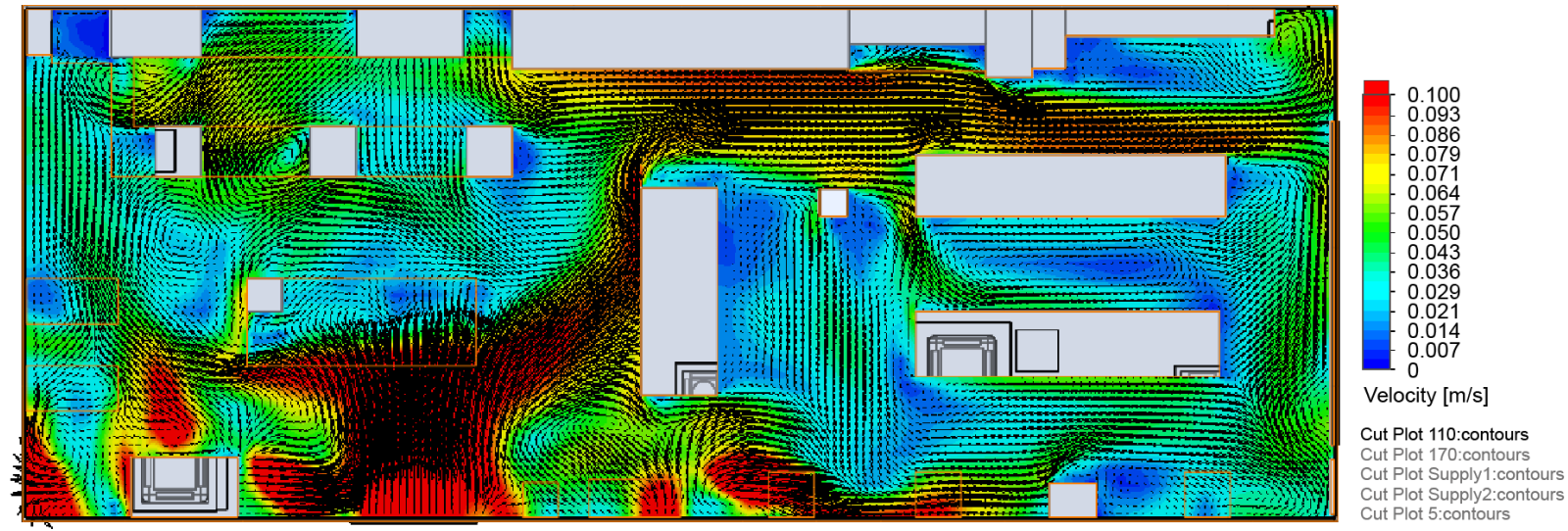

(b)
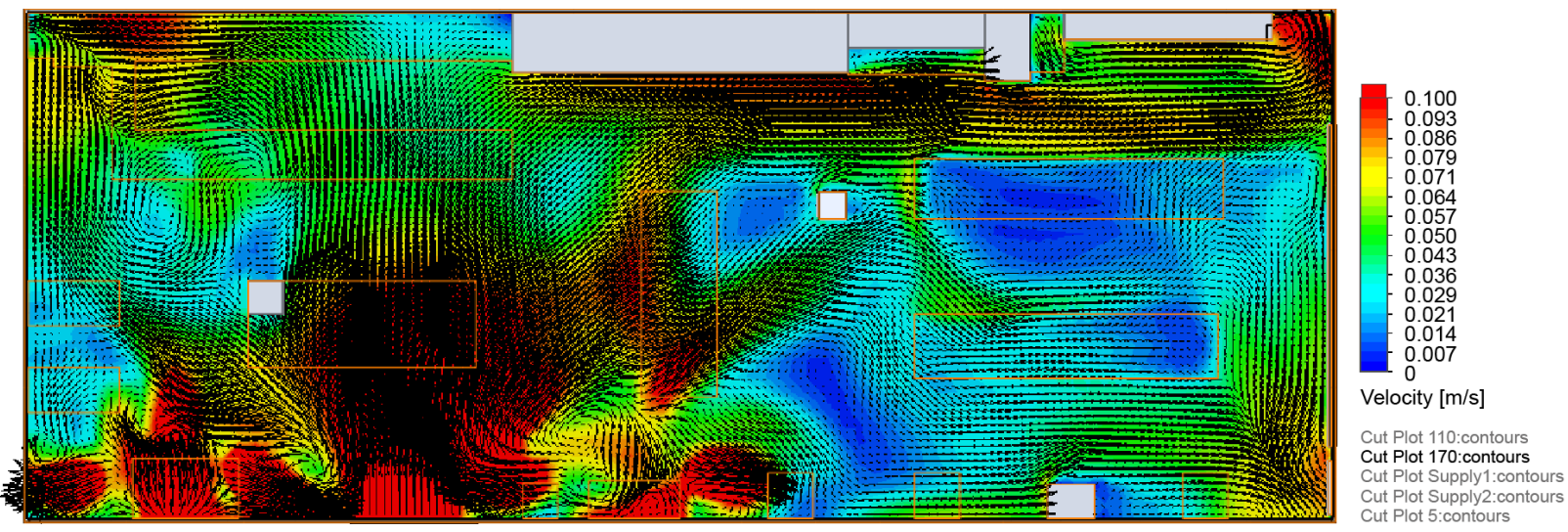

Figure 9. The airflow distribution of CFD simulation in the convenience store according to improvement strategy of displacement ventilation. (a) a top view at $110 \mathrm{~cm}$; (b) a tap view at $170 \mathrm{~cm}$.

\section{Conclusion}

In this study, we discussed the difference between indoor airflow and spatial distribution of $\mathrm{CO}_{2}$ concentration in a convenience store on campus. We found that the areas that easily accumulate $\mathrm{CO}_{2}$ in the indoor environment were corresponded to dead zone areas. There was also a similarity between the concentration distribution and indoor airflow trajectory. Thus, the model field established in this study was in line with the actual spatial distribution of airflow and the distribution of pollutant. This model can be used to estimate the spatial distribution of $\mathrm{CO}_{2}$ in the indoor environment. Dead zones were formed in some areas associating with not only indoor ventilation design and indoor airflow but also interior furnishings. Low air velocity increased the risk of dead zones. As a consequence, $\mathrm{CO}_{2}$ accumulated in these areas and the pollutant concentration surpassed the standard value. Additionally, there was a short circuit due to the close distance between the supply air outlet and the return air inlet. The preferred improvement strategies include displacement ventilation, horizontal ventilation, and modifying the air supply angle to $30^{\circ}$. The second-best strategies include opening the entrance door and increasing ventilation openings. Taking expenditure into consideration, the optimal improvement strategy is to modify the air supply angle to $30^{\circ}$. 


\section{References}

[1] Vehviläinen, T., Lindholm, H., Rintamäki, H., Pääkkönen, R., Hirvonen, A., Niemi, O. and Vinha, J. (2016) High Indoor $\mathrm{CO}_{2}$ Concentrations in an Office Environment Increases the Transcutaneous $\mathrm{CO}_{2}$ Level and Sleepiness during Cognitive Work. Journal of Occupational and Environmental Hygiene, 13, 19-29. https://doi.org/10.1080/15459624.2015.1076160

[2] Chung, K.C. and Hsu, S.P. (2001) Effect of Ventilation Pattern on Room Air and Contaminant Distribution. Building and Environment, 36, 989-998. https://doi.org/10.1016/S0360-1323(00)00051-2

[3] Cheong, K.W. and Chong, K.Y. (2001) Development and Application of an Indoor Air Quality Audit to an Air-Conditioned Building in Singapore. Building and Environment, 36, 181-188. https://doi.org/10.1016/S0360-1323(99)00064-5

[4] Clements-Croome, D.J. (2008) Work Performance, Productivity and Indoor Air. Scandinavian Journal of Work Environment \& Health, 4, 69-78.

[5] Lin, Z., Yao, T., Chow, T.T., Fong, K.F. and Chan, L.S. (2011) Performance Evaluation and Design Guidelines for Stratum Ventilation. Building and Environment, 46, 2267-2279. https://doi.org/10.1016/j.buildenv.2011.05.006

[6] Rosbach, J.T., Vonk, M., Duijm, F., Ginkel, J.T., Gehring, U. and Brunekreef, B. (2013) A Ventilation Intervention Study in Classrooms to Improve Indoor Air Quality: The FRESH Study. Environmental Health, 12, 110.

https://doi.org/10.1186/1476-069X-12-110

[7] Norbäck, D., Nordström, K. and Zhao, Z. (2013) Carbon Dioxide $\left(\mathrm{CO}_{2}\right)$ Demand-Controlled Ventilation in University Computer Classrooms and Possible Effects on Headache, Fatigue and Perceived Indoor Environment: An Intervention Study. International Archives of Occupational and Environmental Health, 86, 199-209. https://doi.org/10.1007/s00420-012-0756-6

[8] Panagopoulos, I.K., Karayannis, A.N., Kassomenos, P. and Aravossis, K. (2011) A CFD Simulation Study of VOC and Formaldehyde Indoor Air Pollution Dispersion in an Apartment as Part of an Indoor Pollution Management Plan. Aerosol and Air Quality Research, 11, 758-762. https://doi.org/10.4209/aaqr.2010.11.0092

[9] Li, Y. (2012) Numerical Simulation and Analysis for Indoor Air Quality in Different Ventilation. Health, 4, 1352-1361. https://doi.org/10.4236/health.2012.412197

[10] Alves, C., Nunes, T., Silva, J. and Duarte, M. (2013) Comfort Parameters and Particulate Matter $\left(\mathrm{PM}_{10}\right.$ and $\left.\mathrm{PM}_{2.5}\right)$ in School Classrooms and Outdoor Air. Aerosol and Air Quality Research, 13, 1521-1535. https://doi.org/10.4209/aaqr.2012.11.0321 